Marquette University

e-Publications@Marquette

Economics Faculty Research and Publications

Economics, Department of

$1-1-2008$

\title{
The Conception of the Socially Embedded Individual
}

John B. Davis

Marquette University, john.davis@marquette.edu

Published version. "The Conception of the Socially Embedded Individual," in The Elgar Companion to Social Economics. Eds. John B. Davis and Wilfred Dolfsma. Cheltenham, UK: Edward Elgar Publishing, 2008: 92-105. Permalink. (c) 2008 Edward Elgar Publishing. Used with permission. 


\section{The conception of the socially embedded individual

\author{
John B. Davis
}

Social economics differs in many respects from standard mainstream economics, but one of the most fundamental differences is that it employs a conception of the human individual as socially embedded rather than as atomistic. Indeed, just as the atomistic individual conception is one of the defining characteristics of mainstream economics, so the socially embedded individual conception is one of the defining characteristics of social economics. Broadly speaking, the difference between these two conceptions rests on whether individuals and their behavior are explained 'externally' in terms of their social relationships or 'internally' in terms of their private tastes and preferences. The former perspective sees social life as intrinsic to our understanding of individuals as social beings; the latter perspective operates with a view of social life restricted to the market interaction of individuals understood as non-social beings. It follows that these two conceptions of the individual also support two different normative visions of individuals and society. The socially embedded individual conception is associated with normative principles that emphasize relationships between people, such as equality, fairness and the (positive) freedom to achieve, whereas the atomistic individual conception is associated with normative principles that emphasize the independence of individuals, such as autonomy, rights and (negative) freedom from social interference. We can characterize the former approach as a social justice view and the latter approach as a liberal society view. Each has strongly contrasting social economic policy recommendations associated with it, particularly with respect to the role given to the market in modern economies, and indeed much of modern history can be explained in terms of conflicting horizons laid out by these two views.

This chapter is devoted to explaining the socially embedded individual conception. Given that there are many ways in which social relationships can be discussed, there are also many ways in which individuals can be understood to be socially embedded. The first section of the chapter accordingly surveys a variety of recent contributions to this understanding, giving attention both to those that explicitly develop socially embedded individual conceptions and also to those that do so more indirectly by 
criticizing the standard atomistic individual conception. The second and third sections then discuss two fundamental issues raised by these contributions: (a) the relation of social identity to personal identity, and (b) the problem of inequality. The fourth section closes the chapter with comments on how thinking about individuals in economics may evolve in the future.

\section{Recent contributions to the conception of the socially embedded individual}

An important challenge to the conception of the socially embedded individual is to explain how individuals can still be individual when socially embedded. There has been a long debate in economics between proponents of methodological individualism - the idea that economic explanations should take individuals as entry points - and proponents of methodological holism - the idea that economic explanations should take social aggregates (such as classes, social groups etc.) as entry points. Critics of the atomistic individual conception who also reject methodological individualism thus often also adopt methodological holism as their perspective, and accordingly sometimes find themselves treating 'socially embedded individual' as an oxymoron. Their reasoning is that as social structures are primary, they must be determinative of individual behavior (just as methodological individualists argue that as individuals are primary, they must be determinative of social structures). But both perspectives are too narrow since it can be argued that social structures influence individuals and that individuals also influence social structures, and thus that each constitute independent agents. On this wider view, then, 'socially embedded individual' is a meaningful conception whose understanding requires the analysis of both types of influences.

This has been done by many in connection with a cross-disciplinary social science and philosophy investigation termed structure-agency theory, whose premise is that individuals and societies both need to be explained in terms of their mutual influences upon one another. Sociologist Mark Granovetter stated this in an especially influential way in arguing that socially embedded individuals are neither 'atoms outside a social context' nor beings who 'adhere slavishly to a script written for them by the particular intersection of social categories they happen to occupy' (Granovetter, 1985, p. 487). Sociologist Anthony Giddens advanced one particular view of structure-agent interactions he termed 'structuration theory', which treats individuals and social structures as interdependent and inseparable or as a duality of structure (Giddens, 1976). Economist Tony Lawson argues that 'social structure [is] dependent upon human agency . . . open to transformation through changing human practices' (Lawson, 1997, p. 158). 
But how is it, we should ask, that individuals are indeed agents when social structures are said to affect them? Put differently, how can we invest individuals with a relative autonomy when we recognize they are acted upon by society? The answer lies in deepening the concept of the individual as an agent to include the idea of being a reflexive being. A long history of social psychology (cf. Davis, 2003, pp. 114ff.) treats individuals as reflexive beings in virtue of their ability to form self-concepts and engage in different kinds of self-referring behavior. Of course social factors influence how individuals form self-concepts, but the idea that they are able to reflexively take themselves as subjects as objects of their thinking and activity, or objectify themselves as subjects, implies that individuals can detach themselves in some degree from the determining effects of social factors influencing them. This relative detachment allows us to suppose that individuals also influence social structures, just as social structures influence individuals, and enables us to then treat the idea of the individual being socially embedded as a coherent and meaningful conception.

We can accordingly first distinguish explicit contributions to the socially embedded individual conception as those that employ some sort of structure-agent modeling of individual and society and which characterize individuals in some fashion as reflexive beings. Six different types of contributions fall within this description: social economic, institutionalist, critical realist, feminist, intersubjectivist and expressivist.

The social economic conception of the socially embedded individual is often referred to as Homo socio-economicus (O'Boyle, 1994). As Mark Lutz puts it, 'persons as social individuals are embedded in a web of constitutive social relations' (Lutz, 1999, p. 6) such as community, family, and a variety of wider social relationships, all of which support different sets of social values that individuals rely upon to guide their daily lives. Economic relationships, such as consumption, production and exchange, then, are framed by these constitutive social relations, so that social values always underlie economic values. Lutz accordingly explains the individual as a dual self in that individuals possess first-order preferences over goods and work and also second-order or social value preferences over these first-order preferences. David George uses this framework to argue that pro-market policies often promote first-order preferences at the expense of second-order ones, as for example when individuals are encouraged to consume products they believe they should avoid (George, 2001). Amartya Sen brings out the reflexivity inherent in this dual self-conception of the individual when he characterizes individuals as beings able to engage in rational self-scrutiny (Sen, 2002). One way in which individuals can be seen to exercise rational self-scrutiny in their interaction with others is captured by collective intentionality theory. When individuals express intentions using the 'we' 
pronoun, they need to ask themselves whether those to whom the 'we' applies would agree with what they express (Davis, 2003, ch. 7). In such settings, individuals are both influenced by social relationships and social structures, and influence them as well, with the latter depending upon their ability to place themselves in social contexts.

Thinking about the individual in institutionalist economics goes back to Charles Cooley's 'looking-glass self' that makes how individuals judge themselves a matter of how they believe they appear to others (Cooley, 1902, pp. 179ff.). George Mead's symbolic interactionism later expanded this view to include the idea that the mind and self are products of social processes (Mead, 1934), so that self-reflection is embedded in social life. Institutionalism originates in the evolutionary views of Thorstein Veblen and the idea that social processes evolve. In a structure-agent framework, the evolution of the economy as a social economic process involves "both the dependence of institutions upon individuals and the molding of individuals by institutions' - both 'upward and downward causation' processes (Hodgson, 2000, p. 326). Upward causation, which occurs when individuals influence and create institutions, depends upon learning seen as a recursive social practice. Individuals develop habits around social rules and customs in their social environment, but modify those habits as they adjust them to their own circumstances. At the same time, individuals not only rely on social rules and customs and tailor them to their own cases, but they also do this as social rules and customs themselves evolve in response to the actions of individuals (Dolfsma, 2002). The institutionalist learning-based view of individuals, then, treats individuals as socially embedded, reflexive beings constantly adjusting to their own changing circumstances in a historical process that is itself dynamic.

Tony Lawson develops a critical realist understanding of the structureagent model that makes 'social structure dependent upon human agency ... open to transformation through changing human practices which in turn can be affected by criticising the conceptions and understandings on which people act' (Lawson, 1997, p. 158). Social structure changes because human practices change as a result of individuals' reflection upon them and their place within them. Lawson characterizes the rationality of individuals thus understood as a 'situated rationality' in which individuals occupy social positions structured by rules, obligations and the powers that accompany them, and act within this social space. Much of this activity is routinized and relies on tacit knowledge and skills that individuals exercise unconsciously. Yet that this activity can become conscious means that it can still be seen as intentional. The overall structure-agent model that Lawson employs, then, is one in which social structures and human agency coevolve in social processes that reproduce and transform them both. 
Individuals are reflexive beings, but the basis on which they are is continually changing. This arguably produces a need in individuals for an 'inner security' in the form of 'a significant degree of continuity, stability and sameness in daily affairs' (ibid., p. 180). Put in terms of the concept of the individual, socially embedded individuals exhibit a need for an 'ontological security' that preserves their status as individual agents in a social world that is constantly changing.

Feminist economists emphasize the social construction of individual life in terms of such social identities as gender, race or ethnicity, nationality, etc. As Nancy Folbre puts it, 'individuals are so embedded in a complex structure of individual and collective identities and competing interpretations of these that sometimes they do not even know whose interests they are acting on' (Folbre, 1994, p. 16). For example, women have quite different social identities associated with work and family, and often find their responsibilities to each domain in conflict. This shows, however, that individuals cannot be reduced to their social identities, since they must determine how they organize and negotiate these different domains. In this regard, they are reflexive beings who evaluate how they believe they fit into the social relationships they occupy. At the same time, how many individuals together respond to their many social relationships in turn influences the development of social structures themselves. One manifestation of this is social economic policy designed to improve the capacity of women to operate in multiple domains, such as legislation aimed at discriminatory practices in the workplace that penalize women for household caring responsibilities. Thus feminists also employ a socially embedded individual conception, and treat individuals and social structures as mutually influencing.

Two additional conceptions of individuals as socially embedded are intersubjectivist economics (or French conventions theory) and the expressivist individual view. Intersubjectivist economics (Dupuy, 1989; Orlean, 1992; Thévenot, 1989) draws on the phenomenon of speculation in financial markets to argue that 'what we think, desire and decide as economic actors depends a great deal on what other actors are seen to think, desire, and decide' (Fullbrook, 2002, p. 2). Individuals thus explained exhibit strategic rationality, whereby they take into account whether others will cooperate or compete, and also a communicational rationality, whereby they make shared commitments to various norms and social conventions. The expressivist individual view is developed by Shaun Hargreaves Heap (2001), who focuses on individuals' reflective capacities and sense of self-worth, and Philippe Fontaine (1997), who focuses on the differences and relationships between individuals' sympathetic and empathic identification with others. Both views are influenced by Adam 
Smith's 'impartial spectator' perspective that individuals can adopt to judge their relations to others (Smith, 1976 [1759]).

In addition to these six socially embedded individual conceptions, there exist contributions to thinking about the individual in economics in recent mainstream economics that make more indirect contributions to thinking about individuals as socially embedded. Two are discussed here. Behavioral economics, whose origins lie in psychology, and complexity economics, whose sources are physics and biology, both make cases for seeing individuals as socially embedded by criticizing different aspects of the standard atomistic individual conception.

Behavioral economics emphasizes the need to replace the standard view of the individual as Homo economicus by a more realistic conception of the individual as Homo sapiens. Whereas the former is a hyperrational being, for the latter 'the degree of rationality bestowed to the agents depends on the context being studied' (Thaler, 2000, p. 134). Of course 'context' can mean many things, and indeed in much of behavioral economics research it is treated as a relatively abstract principle. For example, contrary to the standard view of choice, behavioralists argue that individual decisionmaking exhibits framing effects and reference-dependence reflecting the anchoring of choice in particular circumstances (Tversky and Kahneman, 1991). But many of the applications of these concepts give the principle of context important social content. Thus framing effects and the referencedependence of choice have been shown to produce hyperbolic time discounting, which implies that people tend to ignore the future. Behavioralists have accordingly recommended social economic policies that correct for this bias (e.g. Madrian and Shea, 2001), thus translating an abstract principle of context into a social one. Context, then, socially embeds individuals, and the atomistic individual conception that ignores context fails to represent individuals adequately.

Complexity economics investigates economic systems that exhibit nonlinear dynamics, and uses an approach termed agent-based modeling to represent individuals in such systems (Tesfatsion, 2006). In contrast to standard economics with its single conception of the individual as an abstract atomistic being, complexity economics assumes agents or individuals are interactive and heterogeneous, and then explains the non-linear dynamics of different economic systems in terms of the co-evolution of different kinds of agents' expectations of each other and the systems they jointly occupy. For example, Alan Kirman's fish market model distinguishes buyers who tend to be loyal to certain sellers from buyers who regularly visit many different sellers, and then investigates how one particular fish market (in Marseille, France) evolves patterns of prices and distribution that reflects specific social-historical circumstances (Kirman, 2001). 
Another example is the Santa Fe stock market model (cf. Arthur, 1995), which looks at different populations of agents, and traces the movement of asset values that results from their interaction over time. As do the behavioralists, complexity theorists fault the atomistic individual conception as a key obstacle to more realistic explanations of economies, and although they do not base their arguments directly on a conception of the individual as socially embedded (as do the six approaches discussed above), they end up making a case for just such a conception.

All eight of the approaches discussed here, then, reject the dichotomy between methodological individualism and methodological holism, and employ some kind of structure-agent analysis in which causal influences operate in two directions. The section that follows addresses two sets of issues that arise in this framework.

\section{Social identity and personal identity}

One particularly important problem that the socially embedded individual conception encounters is the problem of multiple selves. As a conception of the individual that is 'externally' based in social relationships, individuals' multiple selves can be understood to be their different social identities, or how they identify with others. As emphasized by Folbre (1994) and Sen (2006), however, our different social identities often conflict with one another, and this invites us to ask what the unity of the self consists in, and indeed raises the question whether the socially embedded individual is a single being at all. The multiple-selves problem also arises in connection with the atomistic individual conception (cf. Davis, 2003, ch. 4), but that this conception is 'internally' based in the private tastes of individuals arguably makes the problem irresolvable (cf. ibid.). In the case of the socially embedded individual conception, in contrast, it is reasonable to say that individuals have ties to others and also act independently. The question is how this can best be explained.

How, then, does the individual with many social identities still count as a single individual? Extending the identity concept, we can say that individuals with many social identities are single individuals when they are shown to have personal identities consistent with their many social identities. Let us begin to explain this idea by making two points about the concept of social identity. First, defining the concept of social identity as the idea of individuals identifying with others, others may be understood either as (a) social groups, such as are characterized by shared language, ethnicity, religion, work etc., or as (b) simply other individuals, such as friends, family members, neighbors etc. Second, whether social identity takes the social group form or the other individuals' form, the idea of individuals identifying with others can be interpreted in two different ways 
depending on who is responsible for the identification. Either (a) individuals themselves can identify with others, or (b) they can be identified with others by third parties.

These two distinctions allow us to set forth four types of social identity: (1) individuals themselves identify with other individuals; (2) individuals themselves identify with groups of individuals; (3) individuals are identified with other individuals by third parties; (4) individuals are identified with groups of individuals by third parties. These four types are shown in Figure 6.1. Examples of each are: (1) a person identifies with a sick friend; (2) an immigrant identifies with a native language group; (3) social service workers socially identify individuals according to their family dynamics; (4) statisticians socially identify individuals according to race and ethnicity.

Given that we are operating with a conception of the individual as socially embedded, let us then explain an individual's personal identity within this social identity framework. Doing so is consistent with the socially embedded individual conception set out in the last section if we suppose that individuals and social structures are mutually influencing. It is also consistent with seeing socially embedded individuals as reflexive beings if we define the personal identity of socially embedded individuals as an ability to organize and balance their many social identities by

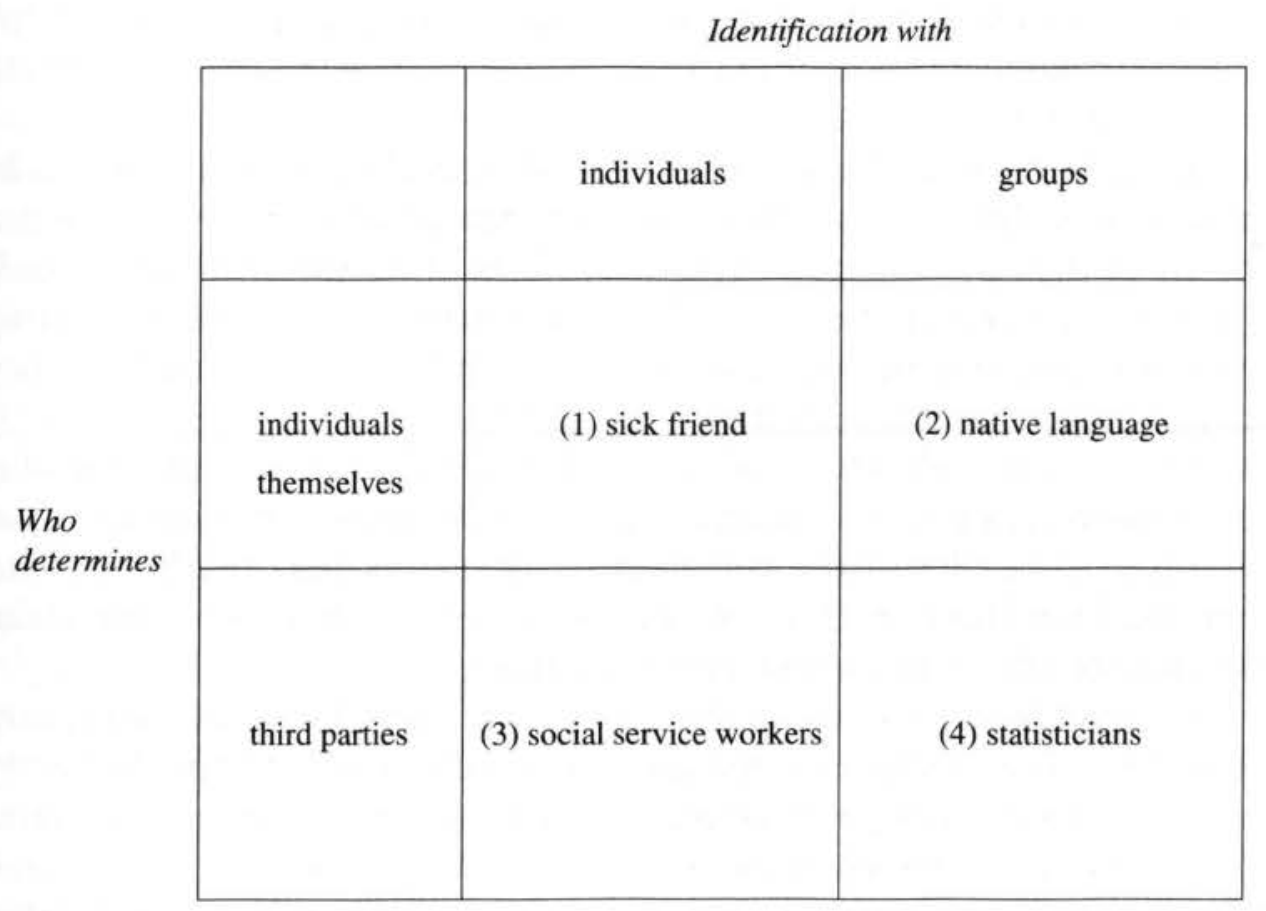

Figure 6.1 Types of social identity with examples 
engaging in self-reflection regarding what their different social ties and social identities involve. We can see better what this involves by applying Figure 6.1.

Consider the two cells in the first row where the difference is between individuals themselves identifying with other individuals or identifying with social groups. Here the ability of individuals to organize and balance their different social identities, understood as maintaining personal identities, is a matter of how they themselves balance these two kinds of connections. For example, an immigrant may identify with a native language group (a social group identification), but put this aside to care for a sick friend (social identification with another individual), also from the same native language group, who does not maintain that social identity. Other combinations of course are also possible, and thus the point is that part of what is involved in individuals having personal identities is how they themselves organize these two types of social identity.

Consider next the second row as contrasted with the first row. The second row explains the social identities of individuals as society sees them, rather than as individuals see them. As a structure-agent framework treats individuals and social structures as mutually influencing, the relationship between personal identity and social identity also needs to capture the influence society has on this understanding. That is, not only do individuals organize and balance their different kinds of social identities (plus the different social identities within each category) in creating personal identities for themselves, but they must also contend with how society sees these balances as well.

For example, in cell (3) a family social worker may make judgments about family dynamics which family members must themselves appraise relative to their own social identifications with one another. Whether such judgments are accepted or rejected then involves individuals in balancing and organizing their personal identities in a way that goes beyond how they see these relations in the absence of third parties. Or, in cell (4), social statisticians classify individuals as members of social groups, which individuals themselves appraise in judging their sense of their social group social identities, since what social statisticians say may or may not be relevant from the individual's perspective. Again, how individuals see their social identities is influenced by how others see them.

The concept of personal identity used here is specific to the conception of individuals as socially embedded, and contrasts with personal identity concepts which ignore or de-emphasize sociality, and rather focus on individuals' psychological characteristics (e.g. Parfit, 1986). The concept here also specifically addresses the concerns of Folbre (1994) and Sen (2006), who recognize that our different social identities often conflict, raising the 
question whether the socially embedded individual is a single being at all. Key to this understanding is the idea of reflexivity, or the idea that individuals can take a position towards themselves. That this individualizes them is due to the fact that individuals can only take themselves as subjects as objects. No one can truly adopt the subject perspective for other individuals. That behaving reflexively also gives a unity to the individual is due to the singularity of this perspective. Yet that personal identity understood in this way is framed in terms of individuals' social identities makes it appropriate for thinking of individuals as socially embedded.

\section{The problem of inequality}

Inequality is an important problem for those concerned with social relationships, and who see individuals as socially embedded. Further, equality is defended as a value by those who derive their normative ideals from social justice views. But if individuals are all unique in having different personal identities in virtue of there being different ways in which they each organize and balance all their different social identities, how should the ideal of equality apply to them? One view of equality inscribed in many nations' laws and constitutions and also in many international covenants and doctrines is that equality is a matter of individuals having equal rights to certain freedoms, such as religion, speech, political participation, cultural commitments and other liberties generally regarded as civil rights. We might accordingly regard these freedoms as foundations for equality. But this understanding of equality only takes us so far toward realizing equality in that having equal civil rights is often compatible with considerable inequality when individuals are economically unequal. Unfortunately, expanding our understanding of equality to include economic equality, particularly as when understood as income inequality, encounters significant conceptual problems. Complete and comprehensive measures of income inequality appear to be unavailable, so that what we are left with at best is a loose 'quasi-orderings' framework whose application is inherently problematic (Sen, 1997).

Faced with these difficulties, Sen recommends asking what the appropriate conceptual 'space' should be in which we investigate inequality, and suggests that we 'concentrate on the individual's real opportunity to pursue her objectives' (ibid., p. 198). His reason is that it is not just income or the goods bought with income that determines how individuals stand relative to one another, but how individuals with their different personal characteristics are able to make use of income and the goods it allows them to buy. Focusing on 'the individual's real opportunity to pursue her objectives' captures this two-sided relation, and changes the 'space' in which we evaluate inequality. Following Aristotle, then, this 'space' can be understood to be 
"the space of "functionings", the various things a person may value doing (or being)' (ibid., p. 199). The approach Sen then develops is the 'capability approach', which represents individuals' real opportunities to pursue their different objectives either in terms of their realized functionings or in terms of the options or alternatives they possess, also understood as their capabilities.

The capability approach thus makes a virtue out of the differences between people, and promises a new approach to the problem of explaining inequality. Basically equality is a matter of individuals being equally able to pursue their real opportunities or capabilities. But what does this involve? Since any given individual has many capabilities, they might be more or less successful in their pursuit of their capabilities according to how many of them they are able to pursue. Individuals might then achieve equality in some respects - for example, being well housed, having good nutrition, and having adequate health care - but not achieve equality in other respects - for example, education. This problem has led to arguments that there ought to be a list of basic or essential capabilities, all of which individuals should be able to achieve if equality is to be achieved (Nussbaum, 2003). Sen, however, believes there cannot be one single list of essential capabilities, because we cannot anticipate what capabilities people will wish to pursue in the future, because we cannot know what future individuals will understand about their world and wish to value, and because it would be a denial of democracy to determine a list for others (Sen, 2005).

Nonetheless, there seems to be one basis on which equality might still be understood in the capability framework. It is suggested by Sen in his Aristotelian rationale for making the 'space' in which we investigate inequality the real opportunities-capability space when he says we need to shift our focus to the 'various things a person may value doing' (Sen, 1997, p. 198). The idea that individuals are able to determine what they value is very close to the idea that they are able to reflexively evaluate themselves relative to their options. In order to determine what one values, one must ask how one's options fit into one's conception of oneself. This conception can of course be changing as one pursues various objectives and creates new ones. Indeed, there is an obvious dynamic involved in individuals pursuing the things they value doing over their lifetimes that is often framed in terms of the idea of personal development.

How does this, then, link up with the idea of equality as a normative ideal? The previous section defined the personal identity of socially embedded individuals in a reflexive way as individuals' ability to organize and balance their many social identities through engaging in a process of selfreflection regarding what their different social ties and identities involve. Although Sen's emphasis on the 'various things a person may value doing' 
is not immediately framed in terms of individuals' management of their different social identities, this latter emphasis is not inconsistent with his, and indeed Sen allows elsewhere that social identity plays a large role in life (Sen, 2006). Thus, if equality is to be determined in the space of capabilities, and what capabilities individuals pursue is determined by individuals themselves, then equality is a matter of individuals being equally able to pursue their personal identities, as they see them. Of course this is a very general view of equality, and it is hardly clear on the surface what would be required to make this ideal a basis for concrete social economic policy. Nonetheless, support for seeing individuals as being able to pursue personal identities as a foundation for equality links up with other normative notions arguably also connected to equality. That is, it can be argued in terms of the reflexivity idea that pursuing a personal identity is tied to such normative values as freedom, having self-respect, and individual dignity (Davis, 2006). Equality as a normative ideal, then, gains in clarity and credibility as it is integrated with and interpreted in terms of other accepted normative ideals.

\section{New directions}

How will thinking about individuals in economics evolve in the future? There has been considerable change in the economics research frontier in recent decades, and all the new approaches that have emerged there in one way or another criticize the atomistic individual conception, and lend support for an understanding of individuals as socially embedded (Davis, forthcoming). In addition, it has long been argued in heterodox economic approaches that the atomistic individual conception does not stand up to critical evaluation, and that individuals are socially embedded. Thus it is worth asking what this apparent shift in thinking may entail, since in the postwar period economics has been strongly structured around the idea that individuals are essentially atomistic.

Consider, then, one influential result on the economics research frontier, a recent laboratory experiment called the public goods game (Fehr and Gächter, 2000). The game/experiment is organized around individuals repeatedly contributing to a public good. In initial rounds of the game contributions are high, but as the game proceeds some individuals free-ride on the contributions of others, ultimately leading most individuals to abandon their contributions, so that the public good is no longer provided. A variation of the game, however, allows individuals to punish free-riders at a cost to themselves, and this reduces free-ridership, and restores the public good. The conclusion that is drawn from this is that the way in which the game is played - with or without punishment - determines its outcome. Whether public goods are provided in real economies, it follows, is also determined 
according to whether punishment of free-riders is possible. Put more generally, how interaction between individuals in economic life plays out is a matter of the kind of institutional structure in which they are embedded.

The public goods game, of course, is a highly simplified experiment meant to illuminate one specific principle, namely, that institutional structure plays a role in determining economic behavior. In contrast, in real economies this kind of simplification tends to conceal rather than illuminate the complex ways in which institutions, social networks, values, habits, inherited beliefs and expectations all interact to create the larger context in which we observe individual behavior. Thus the logical strategy behind the new research in economics that builds on experimental results and sees individuals as non-atomistic is to incorporate increasingly complex institutional considerations into the analysis in an effort to incorporate the role complex social frameworks have in economic life. In effect, the goal is to begin to see the economy as a social economy, where this refers to the larger social space in which economic life occurs.

Thinking about individuals in economics in the future, then, may require considerably more attention to social structure than has been the case in the past, so that what it means for individuals to be socially embedded will depend on a greater understanding of how individuals interact in different and overlapping ways across social-institutional contexts. This would almost certainly constitute an improvement in the understanding of individual interaction in current economics built around atomistic individuals engaged at a distance with one another in markets. The argument of this chapter is that this path of development for economics would preserve the basic outlines of the socially embedded individual conception as set forth here that sees individuals as reflexive beings influenced by and influencing the social structures they occupy.

\section{References}

Arthur, B. (1995), 'Complexity in economic and financial markets', Complexity, 1, 20-25.

Cooley, C. (1902), Human Nature and the Social Order, New York: Scribner.

Davis, J. (2003), The Theory of the Individual in Economics: Identity and Value, London: Routledge.

Davis, J. (2006), 'The normative significance of the individual in economics', in J. Clary, W. Dolfsma and D. Figart (eds), Ethics and the Market: Insights from Social Economics, London: Routledge, pp. $69-83$.

Davis, J. (forthcoming), 'Competing conceptions of the individual in recent economics', in Harold Kincaid and Don Ross (eds), Handbook on the Philosophy and Economics, Oxford: Oxford University Press.

Dupuy, J.-P. (1989), 'Convention et common knowledge', Revue économique, 40 (2), 361-70.

Dolfsma, W. (2002), 'The mountain of experience: how people learn in a complex, evolving environment', International Journal of Social Economics, 29 (8), 675-84.

Fehr, Ernst and Simon Gächter (2000), 'Fairness and Reciprocity', Journal of Economic Perspectives, 14 (3), 159-81. 
Folbre, N. (1994), Who Pays for the Kids? Gender and the Structures of Constraint, London: Routledge.

Fontaine, P. (1997), 'Identification and economic behavior: sympathy and empathy in historical perspective', Economics and Philosophy, 13 (2), 261-80.

Fullbrook, E. (2002), 'Introduction: why Intersubjectivity?', in E. Fullbrook (ed.), Intersubjectivity in Economics: Agents and Structures, London: Routledge, pp. 1-8.

George, D. (2001), Preference Pollution: How Markets Create Desires We Dislike, Ann Arbor, MI: University of Michigan Press.

Giddens, A. (1976), Central Problems in Social Theory, Berkeley, CA: University of California Press.

Granovetter, M. (1985), 'Economic action and social structure: the problem of embeddedness', American Journal of Sociology, 91 (3), 481-510.

Hargreaves Heap, S. (2001), 'Expressive rationality: is self-worth just another kind of preferences?', in U. Mäki (ed.), The Economic World View, Cambridge: Cambridge University Press, pp. 98-113.

Hodgson, G. (2000), 'What is the essence of institutional economics?', Journal of Economic Issues, 34 (2), 317-29.

Kirman, A. (2001), 'Market organization and individual behavior: evidence from fish markets', in J. Rauch and A. Casella (eds), Networks and Markets, New York: Russell Sage, pp. $155-95$.

Lawson, T. (1997), Economics and Reality, London: Routledge.

Lutz, M. (1999), Economics for the Common Good, London: Routledge.

Madrian, B. and D. Shea (2001), 'The power of suggestion: inertia in 401(k) participation and savings behavior', Quarterly Journal of Economics, 116 (4), 1149-87.

Mead, G. (1934), Mind, Self, and Society, Chicago, IL: University of Chicago Press.

Nussbaum, M. (2003), 'Capabilities as fundamental entitlements: Sen and social justice', Feminist Economics, 9 (2-3), 33-59.

O'Boyle, E. (1994), 'Homo socio-economicus: foundational to social economics and social economy', Review of Social Economy, 52 (3), 286-313.

Orlean, A. (1989), 'Mimetic contagion and speculative bubbles', Theory and Decision, 27, 63-92.

Parfit, D. (1986), Reasons and Persons, Oxford: Oxford University Press.

Sen, A. (1997), On Economic Inequality, enlarged edn, with James Foster, Oxford: Clarendon Press.

Sen, A. (2002), Rationality and Freedom, Cambridge, MA: The Belknap Press of Harvard University Press.

Sen, A. (2005), 'Human rights and capabilities', Journal of Human Development, 6(2), 151-66.

Sen, A. (2006), Identity and Violence: The Illusion of Destiny, New York: W.W. Norton.

Smith, A. (1976 [1759]), The Theory of Moral Sentiments, eds D. Raphael and A. Macfie, Oxford: Clarendon Press.

Tesfatsion, L. (2006), 'Agent-based computational economics: a constructive approach to economic theory', in Leigh Tesfatsion and Kenneth L. Judd (eds), Handbook of Computational Economics Vol. 2: Agent-Based Computational Economics, Amsterdam: North-Holland, pp. 831-80.

Thaler, Richard (2000), 'From Homo economics to Homo sapiens', Journal of Economic Perspectives, 14 (1), 133-41.

Thévenot, L. (1989), 'Equilibre et rationalité dans un univers complexe', Revue économique, 40 (2), 147-97.

Tversky, Amos and Daniel Kahneman (1991), 'Loss aversion in riskless choice: a referencedependent model', Quarterly Journal of Economics, 106 (4), 1039-61. 